\title{
In situ thermal profiles and laboratory impact experiments on iceberg ice
}

\author{
R. E. Gagnon, ${ }^{1}$ P. H. Gammon ${ }^{2}$ \\ 'Institute for Marine Dynamics, National Research Council of Canada, St. John's, Newfoundland AIB 375 , Canada \\ ${ }^{2}$ Consolidated Technologies Limited, 37 Stavanger Drive, St. John's, Newfoundland A1A 5E8, Canada
}

\begin{abstract}
A series of 40 impact tests was conducted on large right-circular cylinders $(68.5 \mathrm{~cm}$ diameter and $25.7 \mathrm{~cm}$ thickness) of iceberg ice collected from an iceberg in Labrador. Temperature profiles were also obtained for the iceberg and the profiles exhibited differences associated with the probe location. Temperatures as low as $-15^{\circ} \mathrm{C}$ were measured at penetration depths of about $8 \mathrm{~m}$. The impact specimens were confined at the perimeter and base by a rigid metallic ring and plate. A spherically terminated impactor, with center-mounted pressure transducer, was dropped on to the flat top surface of specimens from various heights and with various added masses. Impact velocity varied from 1.8 to $3.9 \mathrm{~m} \mathrm{~s}^{-1}$; impactor mass varied from 155 to $510 \mathrm{~kg}$ and the ice-specimen temperature varied from $-0.5^{\circ}$ to $-14.5^{\circ} \mathrm{C}$. Peak center pressures averaged from about $25 \mathrm{MPa}$ at the highest temperature to about $41 \mathrm{MPa}$ at the lowest temperature, with the highest recorded pressure being $50 \mathrm{MPa}$. Crater volume increased with increasing impact energy, as expected; however, the specific energy of the ejected material was found to decrease as the energy of impact and crater volume increased. A mechanism for this observed behaviour is proposed.
\end{abstract}

\section{INTRODUCTION}

The development of offshore resources in cold-water environments (e.g. North Atlantic) poses unique challenges because of hazards associated with sea ice and icebergs. It is not unusual during any particular year for there to be several hundred icebergs roaming in a generally southward trek along the East Coast and Grand Banks of Newfoundland. The problems associated with sea ice and icebergs differ considerably because of geometrical aspects of the ice/ structure interaction. In both cases, however, the material properties of the ice have to be known. For design and operational purposes, this enables quantitative determination of the threat stemming from the circumstances of any particular interaction.

To assess the structural requirements for offshore resource development off the East Coast of Canada, Mobil Oil Corporation funded the first phase of a major research program to study the physical and mechanical properties of iceberg ice in 1981-82. Large quantities of ice were collected from a grounded iceberg in Labrador and smaller amounts from three icebergs in Greenland and a Greenland glacier. Impact tests, triaxial tests and beam-bending experiments were performed on the ice in the laboratory. The data from the beam-bending experiments and triaxial experiments have been published (Gagnon and Gammon, 1995a, b). This paper reports the results from the impact component of the test program and field measurements of the temperature distribution within the iceberg in Labrador. Subsequent to publishing a preliminary report of the impact data (Gammon and Gagnon, 1996), we now present a rigorous analysis.

\section{DESCRIPTION OF THE THERMAL PROBE UNITS}

Ice-strength properties are known to be strongly influenced by temperature. Therefore, to realistically determine the behaviour of iceberg ice in an impact situation with a ship or structure requires knowledge of the temperature distribution within the ice. Towards this end, part of the fieldwork involved determining temperature profiles at various locations on the iceberg using thermal probes.

The iceberg (Fig. 1) was aground in about $52 \mathrm{~m}$ of water

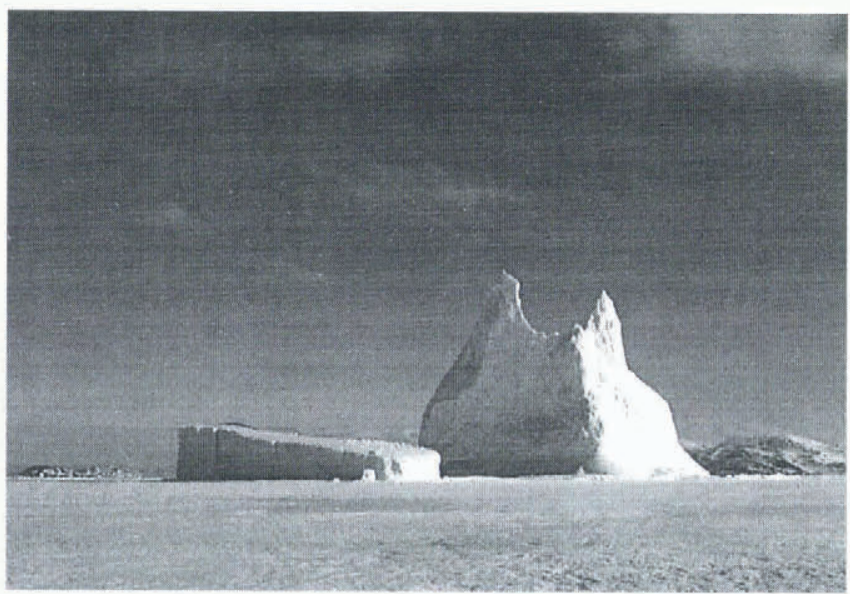

Fig. 1. View of the Labrador iceberg. The iceberg is grounded in Okak Bay and surrounded by sea ice. The pinnacled feature on the right is approximately $60 \mathrm{~m}$ in height and the sloping tabular feature on the left is about $16 \mathrm{~m}$ maximum height. There is a dry-dock area between the pinnacled and labular features. 
in Okak Bay, Labrador $\left(57^{\circ} 39^{\prime} \mathrm{N}, 61^{\circ} 50^{\prime} \mathrm{W}\right)$. The estimated mass of the iceberg was $0.6 \mathrm{Mt}$. The above-water profile consisted of a pinnacled area, with height of approximately $60 \mathrm{~m}$ and a sloping tabular area of approximately $16 \mathrm{~m}$ maximum height with a dry-dock region in between. Figure 2 shows a plan-view drawing of the Labrador iceberg indicating its prominent features, the location of the ice-quarrying site and the positions of the six thermal probes.

Each thermal drill unit consisted of two lengths (approximately $61 \mathrm{~m}$ ) of flexible nylon tubing bound together side-by-side by tight-fitting heat-shrink material. One tube supplied hot circulating fluid to the drilling head while the other served as the return line. The tubing was wound on to a portable reel which facilitated convenient deployment in the field. The nylon tubing was connected at one end to the thermal drilling head, a copper heat-exchange device, consisting of loops of $3 \mathrm{~mm}$ diameter copper tubing, which efficiently transferred heat from the circulating fluid to the ice, thereby melting a channel through which the probe could pass. Also, to minimize arcing of the probe trajectory as it penetrated the ice, hollow stainless-steel stiffeners $1 \mathrm{~m}$ in length were inserted into the ends of the nylon tubes before the drilling head was attached. The other end of the tubing was connected to a pump capable of delivering fluid at $1.03 \mathrm{MPa}$ at a rate of $72 \mathrm{~cm}^{3} \mathrm{~s}^{-1}$.

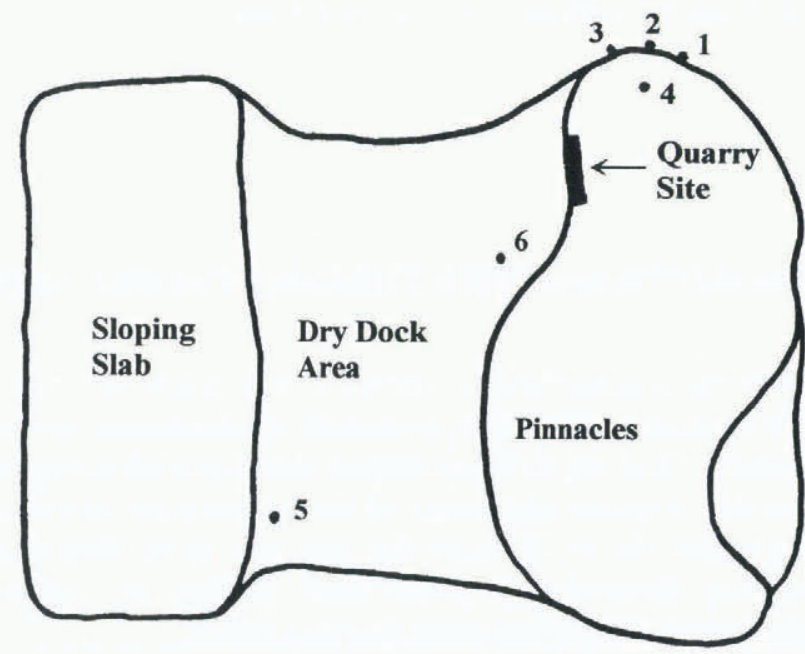

Fig. 2. Plan-view drawing of the iceberg showing its prominent features, the ice-quarry site and the locations of the six thermal probes.

Water, driven by an electric pump, was used as the circulating medium during drilling. The circulating water was heated via a heat exchanger which was totally immersed in hot solution (approximately $70^{\circ} \mathrm{C}$ ) during operation of the drilling system. After the drill had reached the desired depth, a glycol-water mixture was pumped into the nylon tubing to prevent freeze-up during thermalization.

The pump was then shut down and the reel of nylon tubing terminated. The tube ends which protruded out of the iceberg were plugged to prevent inadvertent drainage of the glycol mix. After thermalization (at least $14 \mathrm{~h}$ ), a plug was removed from one side of the tubing and the thermistor unit was fed down. A Fluke multimeter was used to obtain readings of resistance vs depth which were recorded at $10 \mathrm{~cm}$ intervals. Subsequently, a second profile was obtained by inserting the thermistor down the other side of the nylon tubing. Both profiles were invariably identical.

\section{ICEBERG TEMPERATURE PROFILES}

Table lindicates the entry-point elevation for each probe relative to the water line (water line was defined as the maximal tidal height) and also the estimated angle of entry relative to the normal to the ice surface at that point.

Table 1. Thermal-probe elevation and angle of insertion

\begin{tabular}{ccc}
\hline Probe No. & $\begin{array}{c}\text { Elevation relative } \\
\text { lo water line }\end{array}$ & $\begin{array}{c}\text { Angle of entry } \\
\text { relative to normal } \\
\mathrm{m}\end{array}$ \\
& & \\
\hline & & \\
1 & -3.3 & 40 \\
2 & -2.6 & 5 \\
3 & -3.4 & 35 \\
4 & 0.3 & 10 \\
5 & 0.6 & 0 \\
6 & 0 & 0 \\
\hline
\end{tabular}

* Negative values indicate below water line.

Figure 3 shows the temperature vs trajectory length for each of the six thermal probes. The temperature profiles indicate that the thermal gradient near the surface (first few meters) of the iceberg was fairly linear. From theoretical considerations of heat diffusion, this is reasonable when one takes into account the size and extent of the ice mass, the fairly constant temperature at the ice surface and the length of time that these conditions prevailed. The abovewater-line ice surface (where probes 4,5 and 6 were inserted) was warm in the spring when the fieldwork was conducted, due to warm air temperatures and solar radiation. Above-water-line surface melting was observed during the warmest part of the day on a number of occasions during

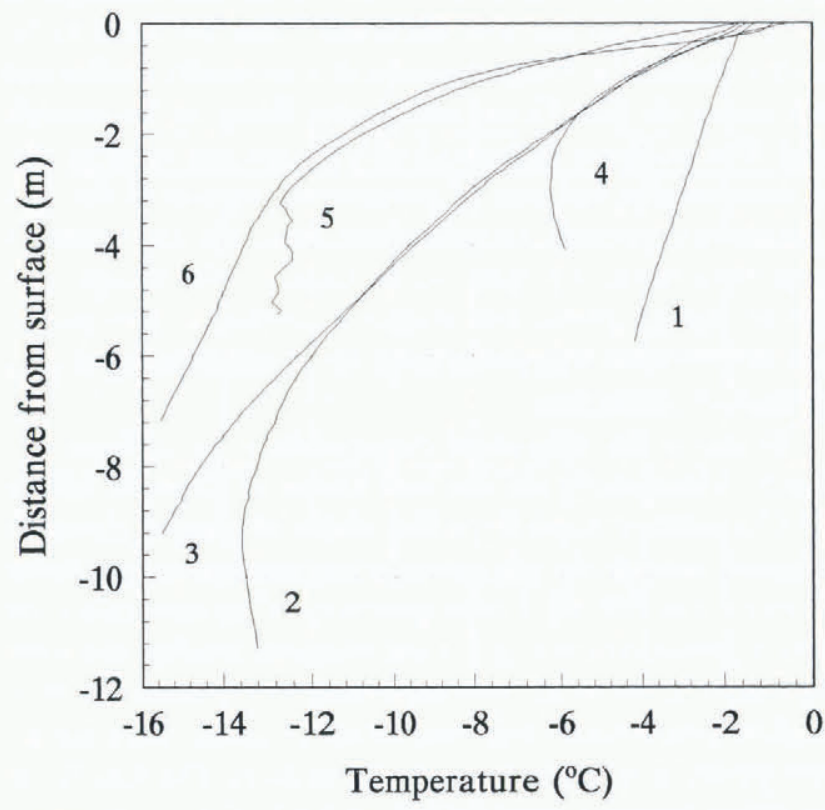

Fig. 3. Distance from surface vs temperature profiles for the six thermal probes. Distance from surface refers to trajectory length irrespective of angle of entry and the possibility of slight arcing of the probe path. The number associated with each probe corresponds to the probe numbers shown in Figure 2 and Table 1. 
the field trip. Below-water-line ice surface was, of course, close to the melting temperature at all times. According to the helicopter pilots, the iceberg had remained in the same location and orientation for a period of at least 1 year.

Two of the above-water-line probes (probes 5 and 6 from the dry-dock area) indicated the highest temperature gradient $\left(\sim-5^{\circ} \mathrm{C} \mathrm{m}^{-1}\right)$ over the initial $2 \mathrm{~m}$ of penetration. The below-water-line probes 2 and 3 indicated a temperature gradient of about $-2.8^{\circ} \mathrm{Cm}^{-1}$ over the first $2 \mathrm{~m}$. The higher gradient in the former case is understandable, since over time the heat transfer from the air and from solar radiation to the interior of the ice would be less efficient than, and not as constant as, heat transfer from water near $0^{\circ} \mathrm{C}$ to the ice surface that was submerged. Hence, the above-water-line ice maintains its original interior temperature nearer the surface, resulting in a higher gradient. The profile for probe 4 is somewhat anomalous. It starts out similar to probes 2 and 3 for the first $2 \mathrm{~m}$ but then is quite different beyond that. This probe is an above-water-line probe, similar to 5 and 6 , but is near the iceberg surface that is submerged (Fig. 2), whereas 5 and 6 are much further from the submerged ice surface. That may at least explain its similarity in the first $2 \mathrm{~m}$ of penetration to probes 2 and 3 . As the probes go deeper, the gradients for 3 and 6 begin to be similar, indicating a diminished influence from surface effects.

Probe 1 exhibits the shallowest apparent gradient of all probes. This is most likely because it was inserted at the shallowest angle of all probes, approximately $40^{\circ}$ to the normal to the ice surface. Only rough estimates could be obtained for the true angle of entry for the below-water-line probes. Another factor that could have contributed to anomalous behaviour of the probe measurements was the possibility of some arcing of the trajectory due to slight bending of the straightening rods behind the probe head, because of the natural curvature of the hard plastic fluid feedlines. This latter effect would have influenced data from probes with shallow angle entries more so than other probes.

In summary, the temperature data indicate that the internal iceberg temperature is at least as low as $-15^{\circ} \mathrm{C}$, reaching that temperature at depths in the ice ranging from about 4 to $10 \mathrm{~m}$, depending on the specific location of the probe relative to the submerged ice surface. The temperature-profile data of Diemand (1984) suggest bulk temperatures of small icebergs around Newfoundland, Canada, to be in the range $-15^{\circ}$ to $-20^{\circ} \mathrm{C}$. Goodrich (1987) obtained temperature profiles of two grounded icebergs over a 2 month period and data from one floating iceberg. He observed near-surface temperature-profile variations as a function of time. Location-dependent profile variations were also evident for the different locations on the iceberg where measurements were obtained, as was evident in the present study. The larger of the two grounded icebergs studied by Goodrich had the greatest similarity to the present iceberg, in terms of size and the fact that it was grounded and had an indicated core temperature of about $-12^{\circ} \mathrm{C}$ at a depth of $15 \mathrm{~m}$. Calculations of temperature distribution within large ice masses floating in water near $0^{\circ} \mathrm{C}$ (Diemand, 1984; Løset, 1993) indicate persistence of the initial temperature within the bulk of the masses for long durations and significant temperature gradients near the ice surface, similar to those observed here.

\section{IMPACT APPARATUS}

The apparatus for conducting impact tests consisted of a spherically terminated cylindrical steel weight instrumented with a pressure transducer and an accelerometer. The weight was hoisted above the ice specimens using a manually powered winch to draw a steel cable attached to the weight through a pulley at the top of a support tower. The tower winch and impact projectile are shown in Figure 4. The impact projectile consisted of up to four segments. The first segment, weighing $154.7 \mathrm{~kg}$ (inclusive of the guide rod used to maintain the projectile orientation) housed the pressure sensor. The pressure sensor consisted of a small hydraulic cylinder with a solid metallic rod $(1.905 \mathrm{~cm}$ diameter attached to the piston of the unit. The rod extended out through a close-fitting hole in the centre of the impactor head. The rod's end surface was flush with the surrounding impactor surface. A diaphragm-type pressure transducer monitored the oil pressure in the cylinder during tests. The resonant frequency of the combined pressure-sensing system was about $1 \mathrm{kHz}$. The projectile tip was machined to a smooth spherical shape with a radius of curvature of $22.9 \mathrm{~cm}$.

Three additional steel cylinders each with a diameter of $33 \mathrm{~cm}$, thickness $19.5 \mathrm{~cm}$ and mass $118.4 \mathrm{~kg}$ provided the

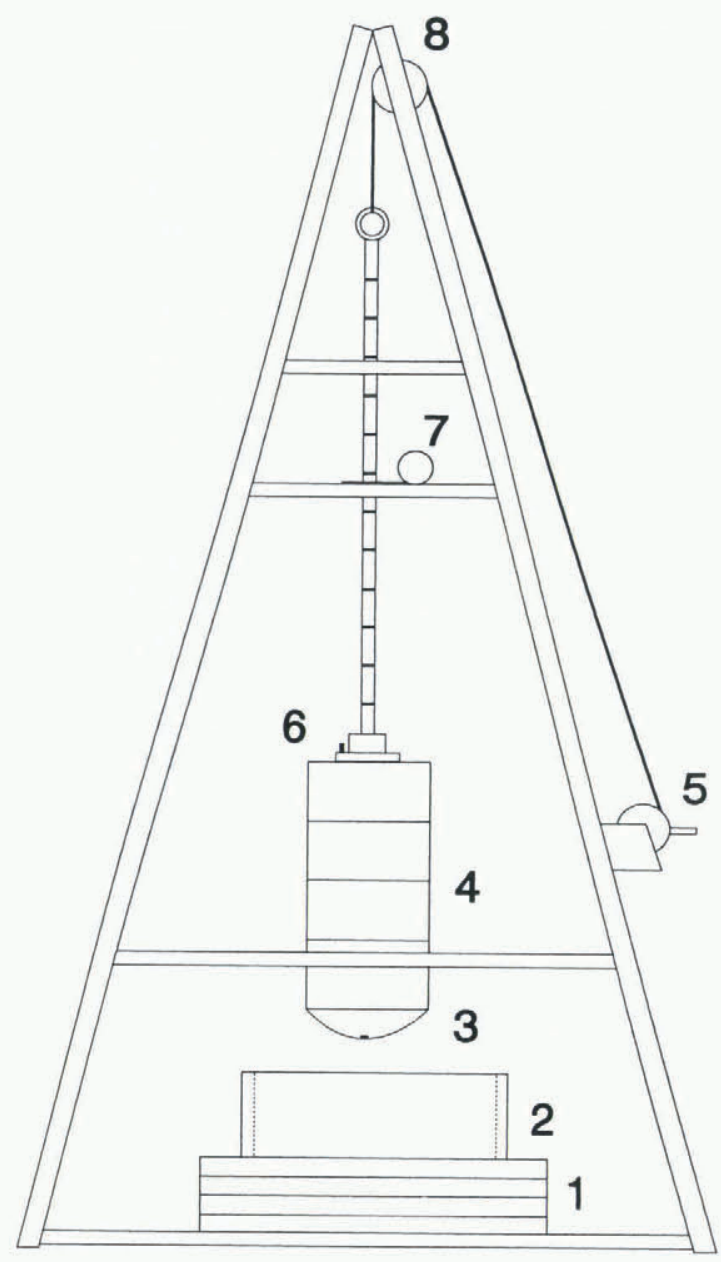

Fig. 4. An orthographic view of the impact apparatus: (I) Inertial base consisting of alternating layers of lead and steel. (2) Aluminum confining ring surrounding an ice specimen. (3) Projectile head with pressure transducer at the tip. (4) Removable steel weights. (5) Winch. (6) Collar with accelerometer attached. (7) Solenoid-release mechanism. (8) Pulley. 
weight of the impact projectile. These cylinders were laid on top of the first segment and were held in position with the $3.18 \mathrm{~cm}$ diameter steel guide rod running through their centers. A steel collar fixed to the guide rod with two set screws and making contact with the top of the uppermost cylinder prevented relative vertical motion of the weights. The collar also served as the base on which the accelerometer was mounted. The accelerometer (PCB Piezotronics model 302A02) provided direct data on the vertical acceleration of the projectile and indirect data (via integration) on the velocity and displacement of the projectile.

The guide rod, attached rigidly to the projectile, passed through two close-fitting sleeves situated $41.5 \mathrm{~cm}$ apart in the upper part of the support tower. The rod completely suppressed rotation and strongly restrained lateral motion of the impact projectile. A series of eight notches spaced $10 \mathrm{~cm}$ apart was cut into the guide rod to provide holding points for a steel pin used to release the projectile into free fall. The release pin was attached by a solenoid, allowing tests to be commenced by throwing a switch located on a bench about $2 \mathrm{~m}$ from the test apparatus. The length of the projectile free fall could be varied in $10 \mathrm{~cm}$ steps from 0.157 to $0.857 \mathrm{~m}$.

The ice specimens used in the impact tests were rightcircular cylinders with a diameter of $68.5 \mathrm{~cm}$ and thickness $25.7 \mathrm{~cm}$. The specimens were radially confined by a $3.8 \mathrm{~cm}$ thick aluminum ring, $26 \mathrm{~cm}$ high which made uniform contact with the perimeter of the specimens. The dimensions of the ring and strength properties of the ring material were chosen so that it provided confinement that simulated an infinite extent of ice around the specimen. The specimens were supported from below by a $2.5 \mathrm{~cm}$ thick aluminum plate bolted down on to an inertial platform. The specimens were frozen to the confining ring and support plate to ensure there was a good fit. The platform consisted of a stack of $121.25 \mathrm{~cm}$ thick steel plates interspersed with lead sheets. The mass of the inertial platform was $790 \mathrm{~kg}$. The platform was supported by a $10 \mathrm{~cm}$ thick concrete floor underlain by $15 \mathrm{~cm}$ of compacted crushed rock.

The data-acquisition system for the impact tests consisted of a HP 85 microcomputer coupled to the test instruments via a high-speed digital data logger. Data acquisition was initiated during a test as soon as a non-zero reading was registered by the center pressure transducer. The data logger then received and digitized data from the pressure transducer and accelerometer at a rate of 8065 samples s $^{-1}$ for each instrument, for about $0.25 \mathrm{~s}$.

\section{PROGEDURE}

In most cases, the temperature of an impact specimen was recorded just prior to its testing. Specimens were allowed to thermalize for a minimum of 5 hours after placement in the confining ring. For the first 11 tests carried out, however, the temperature of the specimen was not measured but was rather inferred using the measured air temperature in the freezer room along with the time of thermalization. The measured values of specimen temperature were obtained by drilling a $0.64 \mathrm{~cm}$ diameter hole $7.6 \mathrm{~cm}$ deep into the ice specimen about $23 \mathrm{~cm}$ from the center. The hole was filled with refrigerated toluene and allowed to thermalize before a calibrated thermistor was inserted, thereupon yielding a measurement of the ice temperature at the bottom. Some residual thermal gradients remained in the samples even after the minimum $5 \mathrm{~h}$ thermalization period. Because of this and the fact that the ice temperature was not measured in all cases, the quoted values of specimen temperature appearing in the discussion below have $\pm 1.5^{\circ} \mathrm{C}$ uncertainty.

Nine of the impact specimens were turned over and reused for a second impact. This procedure was carried out in those cases where the initial impact did not induce major fracturing of the test specimen. Such was the case in most of the low-energy tests and in some of the higher-energy tests where the specimen temperature was near zero.

Table 2 gives detailed characterization data for the ice-

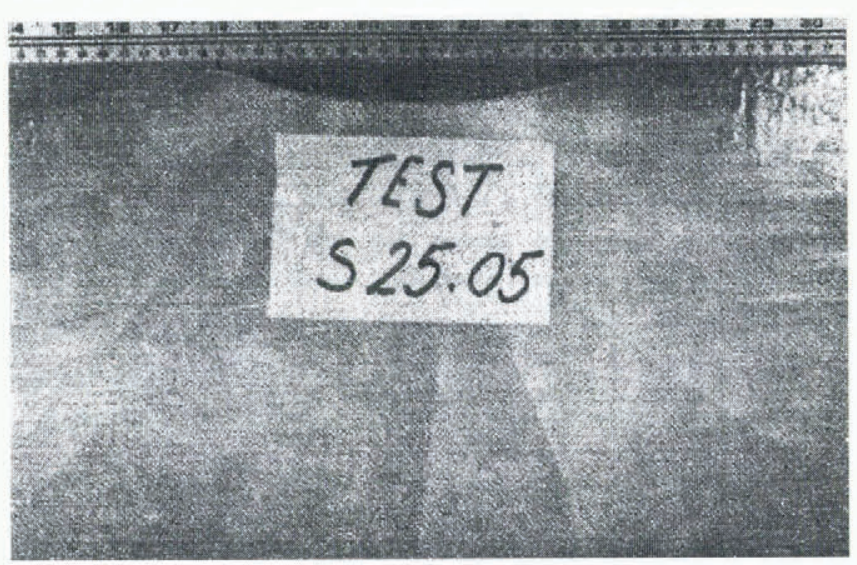

Fig. 5. Side view of an impacted ice specimen (test No. 37 in Tables 3-5) that has been cut down through the center of the impact crater to reveal the crater profile and cracks that radiate from the impact zone. The unit on the lower part of the rule resting on top of the specimen is centimeters.

Table 2. Ice characterization data (Gagnon and Gammon, 1995a)

\begin{tabular}{|c|c|c|c|c|c|c|c|c|c|}
\hline Ice orientation" & $\begin{array}{l}\text { Mean grain } \\
\text { diameter }\end{array}$ & Std. dez. & $\begin{array}{l}\text { Maximum } \\
\text { observed grain } \\
\text { diameter }\end{array}$ & $\begin{array}{c}\text { Mean long and } \\
\text { short bubble } \\
\text { diameter }\end{array}$ & Std. dev. & $\begin{array}{c}\text { Maximum } \\
\text { observed bubble } \\
\text { diameter }\end{array}$ & Bubble density & $\begin{array}{c}\text { Preferred c-axis } \\
\text { orientation }^{\dagger}\end{array}$ & Grain elongation \\
\hline & $\mathrm{mm}$ & & $\mathrm{mm}$ & $\mathrm{mm}$ & & $\mathrm{mm}$ & No. $\mathrm{mm}^{-3}$ & & \\
\hline L.04 & 9.69 & 4.53 & 22.83 & 0.32 & 0.21 & 1.09 & 2.66 & Strong & Moderate \\
\hline L04P & 8.71 & 3.26 & 20.92 & 0.27 & & & & & \\
\hline L04PP & 6.03 & 2.21 & 12.97 & & & & & & \\
\hline
\end{tabular}

* The $\mathrm{L}$ in the designation is for Labrador and the number 04 corresponds to the block of ice from which thin sections were taken. Three mutually orthogonal thin sections were made, distinguished by the absence or presence of a single or double $\mathrm{P}$ (for perpendicular).

${ }^{+}$Moderate preferred $c$-axis orientation implies $20 \%$ of grains align simultaneously to extinction. Strong preferred $c$-axis orientation implies greater than $35 \%$ of grains align simultaneously to extinction. 
berg ice (Gagnon and Gammon, 1995a). The fractional porosity of the ice was $3.5 \pm 0.38 \%$.

After testing, impact blocks were either prepared for a subsequent test or were cut through the middle to reveal a cross-section of the crater (Fig. 5). The cross-sections for those specimens where they could be obtained generally revealed a circular crater profile with a slightly raised rim. The crater was underlain first by a region of finely crushed ice with thickness varying from very thin in some areas up to several millimetres in others, and then by a pattern of tensile cracks radiating into the bulk of the specimen. The degree of tensile cracking was proportional to the impact energy. The depth of the crater formed in each specimen was measured with an adjustable ruled square laid on a steel ruler traversing the top of the sample. These depth readings comprise the set of measured ice-penetration values given in Table 3.

\section{ANALYSIS OF DATA}

As mentioned above, the resonant frequency of the pressure sensor was about $1 \mathrm{kHz}$, which is relatively low for this application, so details of the sharpness of the rise in pressure at the onset of contact could not be resolved. The first contact always produced oscillation in the sensor at its resonant frequency. The first peak in the oscillation was therefore not representative of the actual onset pressure. However, the initial resonation was followed by broader features that could be faithfully detected by the sensor. In spite of the limitation in the sensor response, useful information could still be obtained from the initial oscillatory period. A force transducer can be thought of as a mass-and-spring system. Simple analysis shows that when a force is applied rapidly (i.e. much faster than the response time) to the mass, neglecting damping, it will cause the mass to oscillate on the spring about a certain value of spring compression corresponding to the applied force. Due to overshoot, the maximum spring compression during the oscillation will be about twice the value corresponding to the actual applied force. Hence, in the case of a force applied rapidly to a transducer, a reasonable estimate for the force, or lower limit at least, can be obtained by taking half the amplitude of the first peak in the oscillation. Data from other impact experi-

Table 3. Quantities determined at conclusion of test

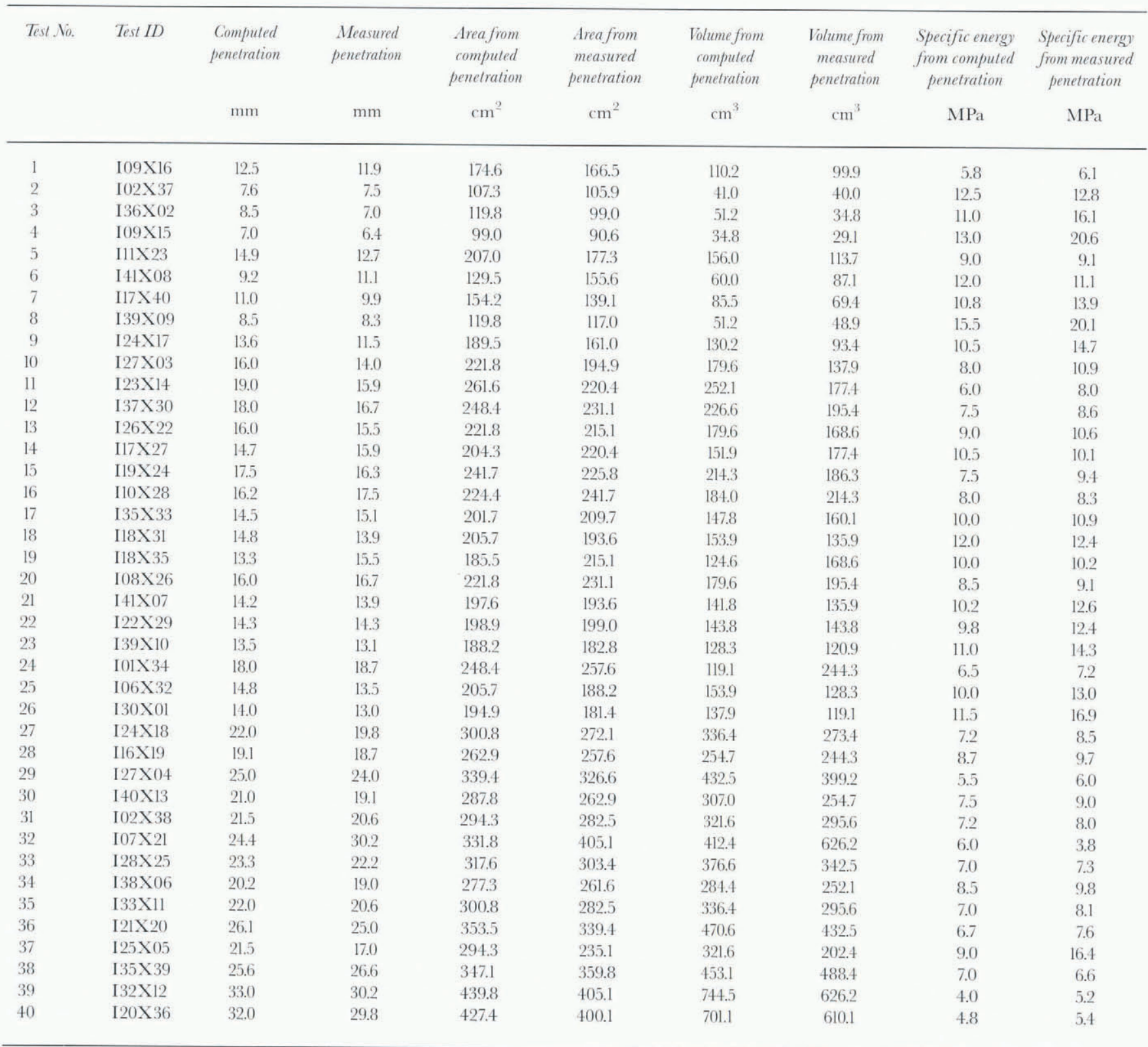


ments on ice indicate that the initial onset of load on pressure sensors occurs in a much shorter time than the response period of our sensor (e.g. Timco and Frederking, 1993). Figure 7 illustrates the behaviour mentioned above. A pressure of $30-40 \mathrm{MPa}$ was applied to the sensor at the onset of impact and maintained for several milliseconds. But, because it was applied rapidly, it caused the sensor to oscillate initially about the actual value, and the first peak in the oscillation is about twice the actual value. Bearing this type of behaviour in mind, the pressure data were analyzed in the following manner to obtain a reasonable value for the maximum pressure attained in each test. The maximum value always occurred somewhere within the first $11 \mathrm{~ms}$. Because the data always showed resonant oscillation at the start, the initial pressure associated with the first peak of the oscillation was taken as one-half the value of the peak. The rest of the data in the first $11 \mathrm{~ms}$ were scanned to see whether the magnitude of any of the broad features exceeded in amplitude the half-height pressure value for the initial resonant peak. Whichever value was greater was taken as the maximum pressure for that particular test.

Most of the data sets comprising the specified end product of the impact test program could not be evaluated without extensive analysis of the raw data. It was necessary to interpolate the first peak of the resonant part of the pressure data for each test by using a least-squares quadratic fit. Also, the output from the accelerometer (Fig. 6) required digital filtering. The filtering, which consisted of up to 25 iterative applications of a three-point smoothing routine, was needed to remove a strong acoustic modulation of the acceleration record. The acoustic modulation was the result of resonant vibrations in the steel guide rod on which the

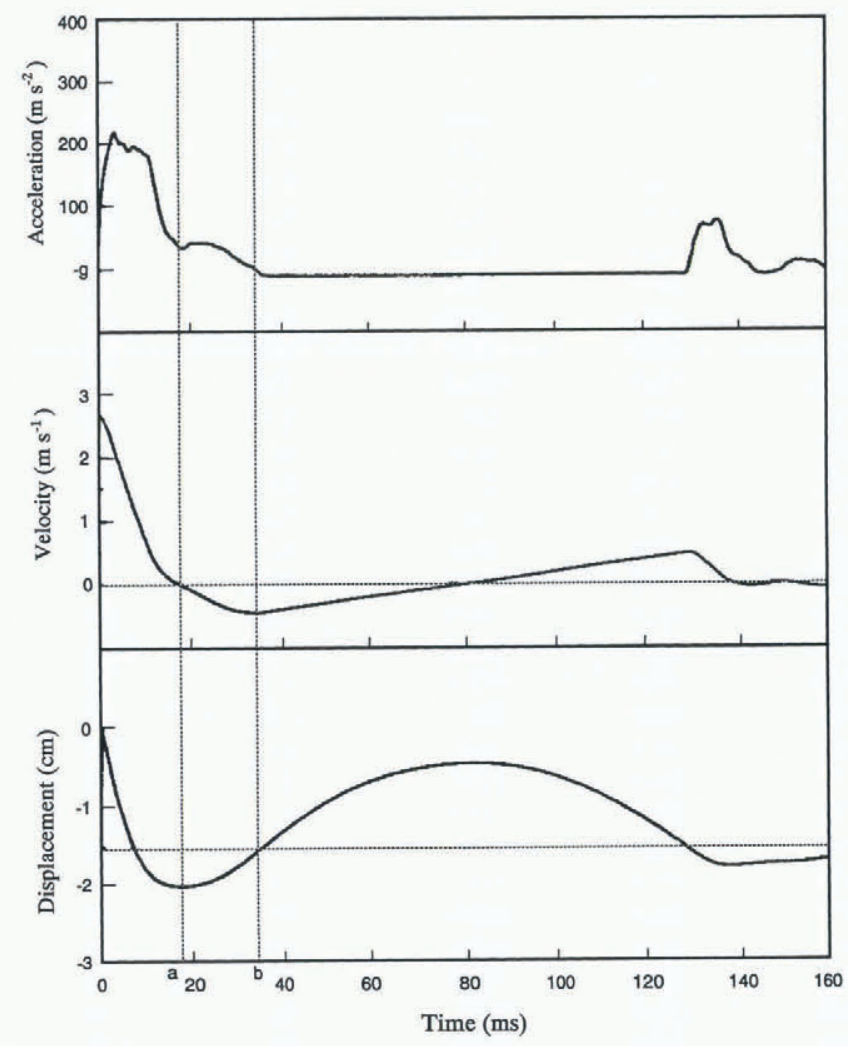

Fig. 6. Plots of projectile acceleration (top), projectile velocity (center) and projectile displacement (bottom) vs time for impact test No. 10 (ID No. I27X03). A projectile of mass $509.8 \mathrm{~kg}$ was dropped from a height of $0.357 \mathrm{~m}$ on to ice at a temperature of $-8.5^{\circ} \mathrm{C}$. collar holding the accelerometer was mounted. Others have observed similar ringing in impact apparatus (e.g. Timco and Frederking, 1993).

It was necessary to integrate the acceleration curve to yield the velocity and displacement of the impact projectile. The integration had the effect of filtering out all remaining high-frequency noise in the acceleration record, but low-frequency or zero-frequency errors in the signal were strongly enhanced. The major cause of low-frequency error in the acceleration values was the non-infinite time constant of the accelerometer-output circuit. This led to a residual exponentially decaying bias in small acceleration values following a period of high acceleration. A second source of systematic error arose from inexact zeroing of the accelerometer output prior to commencement of a test. Because the output was in digital rather than analog form, zeroing was accurate to within one part in 2048 of full-scale acceleration. A final significant source of error lay in the calibration of the accelerometer and the operational amplifiers linking it to the data-acquisition system. This calibration was good to within only $2 \%$ of the reading output of the accelerometer. Hence, error in a peak reading of $200 \mathrm{~m} \mathrm{~s}^{-2}$ could range as high as $4 \mathrm{~m} \mathrm{~s}^{-2}$, although the absolute uncertainty in the majority of the readings lying off the peak was much smaller than this.

In view of the uncertainties described above, integration of raw acceleration data to yield meaningful velocities and displacements was impossible. Accordingly, boundary conditions were imposed on the acceleration curve and its first integral. The readings of acceleration were then corrected to satisfy the boundary conditions and thereby reduce or eliminate the effects of systematic error in the acceleration data. Velocities and displacements referred to in the discussion below are from the analysis described in the Appendix.

\section{RESULTS AND DISGUSSION}

The major results of the impact-test program are tabulated in Tables 3, 4 and 5. The tables list test-identification numbers along with projectile mass, height of drop, initial velocity and impact energy. The tabulated energy values are simply the product of the height of the drop with the gravitational force acting on the projectile. The initial velocity values are determined solely from the height of drop and reflect the projectile velocity at the instant contact was first made with the ice.

Table 4 includes specimen-temperature values along with peak center pressure, peak force and time of peak force. Figure 7 shows center pressure for test No. 10 vs time, plotted on two separate time-scales. The data from 15 of the tests indicated that the peak center pressure occurred near the beginning of the impact within the first millisecond. The peak center pressure occurred sometime later within the first $11 \mathrm{~ms}$ for the other 25 tests.

The peak center pressure was the only direct impact-test output showing a discernible dependence on specimen temperature. Figure 8 shows peak center pressure plotted against temperature with data from all 40 tests included. There was no observed correlation between peak center pressure and projectile mass or projectile velocity. Similar behaviour has been noted by Timco and Frederking (1993). It is also similar to the observations of Kheisin and Likhomanov (1973) and Likhomanov and Kheisin (1971) that the 


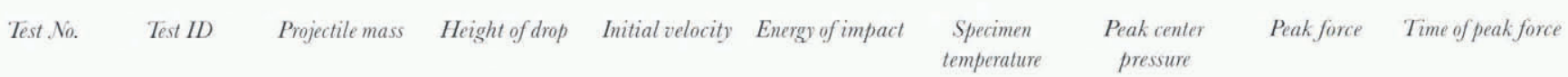

$\begin{array}{llllll}\mathrm{kg} & \mathrm{ms}^{-1} & \mathrm{~J} & \mathrm{C} & \mathrm{N} \times 10^{5} & \mathrm{~ms}\end{array}$

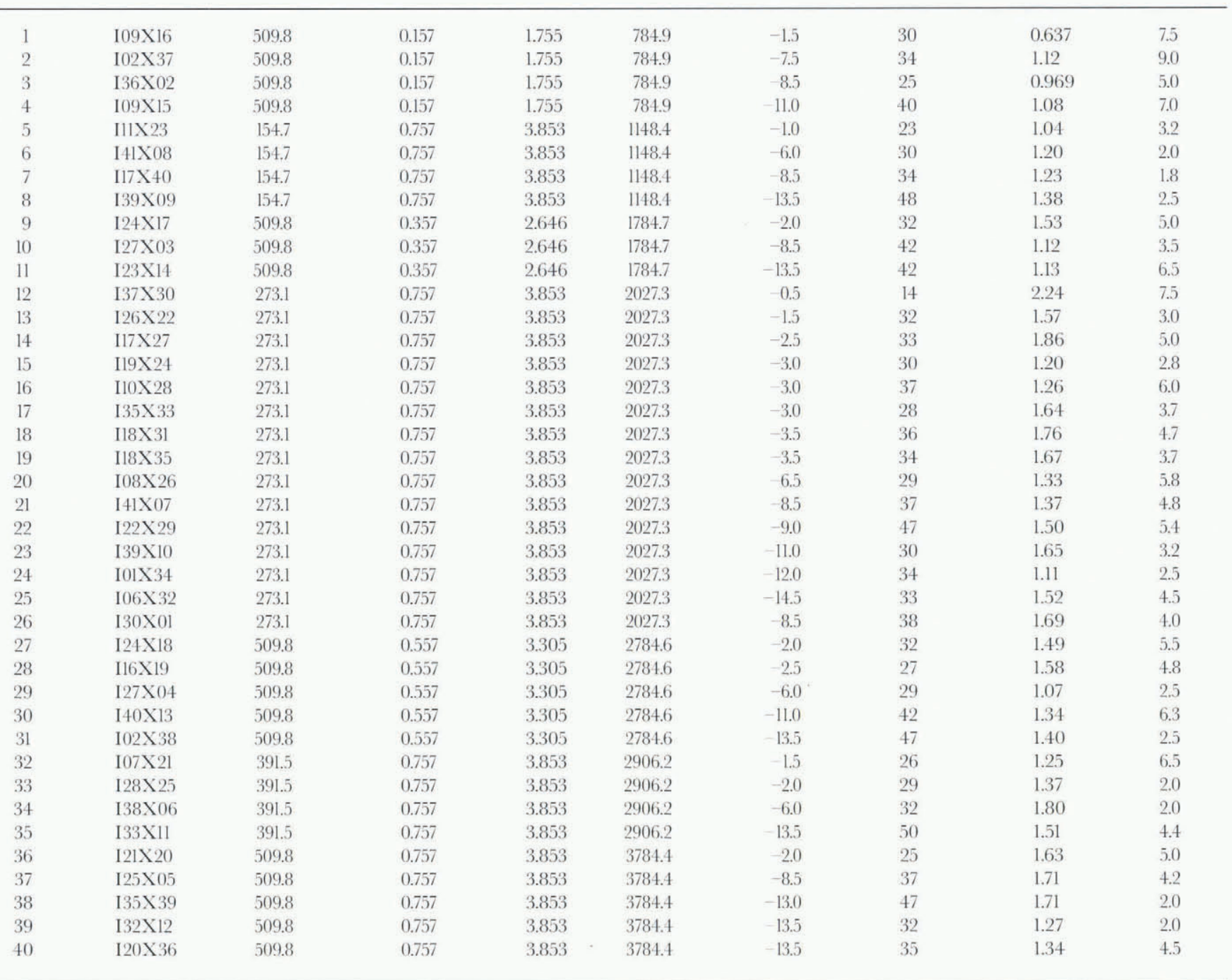

impact crushing strength of ice is almost velocity-independent. The data from impact experiments on sea ice conducted by Chin and Williams (1989) did, however, indicate a dependence of peak center pressure on impact velocity. The peak center pressure in our experiments increased by a factor of about 1.7 over the temperature range $0^{\circ}$ to $-15^{\circ} \mathrm{C}$. Very significant scatter was observed in measurements at all temperatures. The values of peak pressure at the warmer temperatures were near that associated with pressure melting. For example, ice will pressure melt at approximately $42 \mathrm{MPa}$ hydrostatic pressure at $-3^{\circ} \mathrm{C}$. A pressure of $37 \mathrm{MPa}$ was recorded for one of the tests at this temperature. In fact, many of the peak pressures recorded for temperatures warmer than $-3^{\circ} \mathrm{C}$ exceeded that required for pressure melting. The trend of decreasing pressure with increasing temperature would be expected from the meltpoint depression curve for ice. It should be remembered, however, that impact is a rapid dynamic process where the time period at which pressure is highest is very small and insufficient to allow massive heat flow from surroundings to melt large quantities of ice. However, there is another process, the viscous flow of a thin layer of liquid under high pressure (Gagnon, 1994), that can generate melt rapidly during impact and indentation on ice. It is noteworthy that several studies have reported the production of melt during impact and indentation experiments on ice (e.g. Kheisin and Cherepanov, 1970; Gagnon and Sinha, 1991; Gagnon, 1994).

In the discussion below, time to peak force corresponds to the time at which peak acceleration occurred.

The peak force was taken as the product of the projectile mass with the peak acceleration. The time of peak force showed a high degree of scatter but was somewhat correlated with both mass and velocity of the projectile. In particular, high mass and low velocity tended to increase the time to peak force.

Table 5 shows ice penetration, projected area of ice contact and volume of displaced ice, all evaluated at time of peak force. The three quantities were determined from the ice-penetration vs time curves for the respective tests (e.g. Fig. 9). The computed ice penetration was determined by first integrating the acceleration data, with judicious application of boundary conditions to counter systematic errors in the acceleration referred to above, to yield the total projectile displacement (Fig. 6). Then, the floor displacement beneath the ice (Fig. 9) was determined and subtracted to 
Table 5. Quantities determined at time of peak force

\begin{tabular}{|c|c|c|c|c|c|c|c|}
\hline \multirow[t]{2}{*}{ Test No. } & \multirow[t]{2}{*}{ Test ID } & \multirow{2}{*}{$\begin{array}{c}\text { Computed } \\
\text { penetration } \\
\mathrm{mm}\end{array}$} & \multirow{2}{*}{$\begin{array}{l}\text { Area of contact } \\
\mathrm{cm}^{2}\end{array}$} & \multirow{2}{*}{$\begin{array}{l}\text { Volume from computed } \\
\text { penetration } \\
\mathrm{cm}^{3}\end{array}$} & \multirow{2}{*}{$\begin{array}{c}\text { Center pressure } \\
\text { MPa }\end{array}$} & \multirow{2}{*}{$\begin{array}{l}\text { Nominal pressure } \\
\qquad \mathrm{MPa}\end{array}$} & \multirow{2}{*}{$\begin{array}{c}\text { Specific energy from } \\
\text { computed penetration } \\
\text { MPa }\end{array}$} \\
\hline & & & & & & & \\
\hline 1 & I09X16 & 10.5 & 147.4 & 78.0 & 5.6 & 4.6 & 7.5 \\
\hline 2 & I02X37 & 6.5 & 92.0 & 30.1 & 26.0 & 11.0 & 13.0 \\
\hline 3 & I36X02 & 7.0 & 99.0 & 34.8 & 10.0 & 9.5 & 13.0 \\
\hline 4 & I09X15 & 8.2 & 115.7 & 47.7 & 24.5 & 10.0 & 13.0 \\
\hline 5 & IIIX 23 & 10.0 & 140.5 & 70.8 & 12.1 & 7.2 & 10.6 \\
\hline 6 & I $41 \mathrm{X} 08$ & 7.0 & 99.0 & 34.7 & 22.8 & 12.5 & 17.5 \\
\hline 7 & $\mathrm{I} 17 \mathrm{X} 40$ & 5.8 & 82.2 & 24.0 & 22.5 & 13.0 & 19.0 \\
\hline 8 & I39X09 & 7.7 & 108.7 & 42.1 & 32.0 & 13.0 & 18.0 \\
\hline 9 & $124 \times 17$ & 11.1 & 155.6 & 87.1 & 30.0 & 10.0 & 12.0 \\
\hline 10 & I27X03 & 8.3 & 117.0 & 48.9 & 35.0 & 10.0 & 13.8 \\
\hline 11 & I23X14 & 13.7 & 190.9 & 132.1 & 29.0 & 5.9 & 8.0 \\
\hline 12 & I37X30 & 16.2 & 224.4 & 184.0 & 13.5 & 9.5 & 7.5 \\
\hline 13 & I26X22 & 10.5 & 147.3 & 78.0 & 31.0 & 10.0 & 12.0 \\
\hline 14 & $117 \times 27$ & 14.2 & 197.6 & 141.8 & 27.9 & 9.0 & 11.8 \\
\hline 15 & I19X 24 & 9.1 & 128.1 & 58.7 & 13.5 & 8.8 & 11.5 \\
\hline 16 & $\mathrm{I} 10 \mathrm{X} 28$ & 16.0 & 221.8 & 179.6 & 28.8 & 6.0 & 9.0 \\
\hline 17 & I35X33 & 11.7 & 163.8 & 96.9 & 28.0 & 9.9 & 14.5 \\
\hline 18 & I18X31 & 12.7 & 177.3 & 114.1 & 35.1 & 10.0 & 13.5 \\
\hline 19 & Il $8 \times 35$ & 11.9 & 166.5 & 100.2 & 26.4 & 10.0 & 12.8 \\
\hline 20 & 108X26 & 15.6 & 216.4 & 170.8 & 14.5 & 6.5 & 8.5 \\
\hline 21 & I $41 \times 07$ & 13.0 & 181.4 & 119.1 & 16.5 & 7.5 & 12.0 \\
\hline 22 & I22X29 & 14.5 & 201.7 & 148.8 & 44.4 & 6.8 & 10.0 \\
\hline 23 & I39X10 & 10.0 & 140.5 & 70.8 & 28.5 & 12.0 & 15.0 \\
\hline 24 & I01X34 & 8.5 & 119.8 & 51.1 & 22.8 & 9.5 & 13.2 \\
\hline 25 & I06X32 & 12.2 & 170.6 & 105.0 & 30.0 & 9.0 & 12.5 \\
\hline 26 & I30X01 & 12.5 & 174.6 & 110.6 & 35.3 & 9.5 & 12.6 \\
\hline 27 & I24X18 & 15.0 & 208.4 & 159.2 & 13.5 & 6.9 & 9.0 \\
\hline 28 & I16X19 & 13.0 & 181.4 & 119.1 & 19.0 & 9.4 & 12.0 \\
\hline 29 & I27X04 & 7.7 & 108.7 & 42.1 & 21.5 & 10.0 & 14.0 \\
\hline 30 & $\mathrm{I} 40 \mathrm{X} 13$ & 16.2 & 224.4 & 184.0 & 28.5 & 6.5 & 9.8 \\
\hline 31 & I02X38 & 8.2 & 115.7 & 47.7 & 39.0 & 13.0 & 17.5 \\
\hline 32 & I07X2l & 19.0 & 261.6 & 255.5 & 1.1 & 4.8 & 7.8 \\
\hline 33 & I28X25 & 7.5 & 106.0 & 40.0 & 24.0 & 13.8 & 18.8 \\
\hline 34 & I38X06 & 7.0 & 99.0 & 34.8 & 17.2 & 15.0 & 18.0 \\
\hline 35 & I33X11 & 13.3 & 185.5 & 125.2 & 42.7 & 7.6 & 10.0 \\
\hline 36 & I21X20 & 16.2 & 224.4 & 185.7 & 20.5 & 7.1 & 10.0 \\
\hline 37 & I $25 \times 05$ & 13.7 & 190.9 & 132.8 & 31.7 & 9.1 & 12.2 \\
\hline 38 & I35X39 & 6.8 & 96.2 & 32.9 & 45.0 & 17.5 & 24.5 \\
\hline 39 & I32X12 & 7.5 & 106.0 & 40.0 & 8.0 & 12.5 & 17.0 \\
\hline 40 & I20X36 & 15.9 & 220.4 & 178.9 & 0.4 & 6.2 & 10.0 \\
\hline
\end{tabular}

yield the actual ice penetration. The analysis is fully described in the Appendix. No clear correlation could be established between the computed penetration, area of contact and volume of ice from Table 5, and any of the initial test parameters. The high scatter in the depth, area and volume statistics is primarily a result of scatter in the values for the time of peak force.

Figure 10 shows force vs ice penetration at the time of peak force, where all tests are included. The penetration increases as peak force increases. This is not surprising and agrees with other observations (e.g. Fransson and Sandkvist, 1988). Similarly, it was found that ice penetration at the time of peak force strongly correlated with the time of peak force (Fig. 11). When considering all test data together, peak force showed no obvious correlation with the time at which the peak force occurred (not shown here). Nor did tests that had the same test parameters, except temperature, (i.e. tests Nos 12-26) show any clear trend between peak force and time to peak force, except perhaps a very slight positive correlation, with considerable scatter (Fig. 12). Fransson and Sandkvist (1988) observed a positive correlation between peak force and time to peak force for impact tests using simulated iceberg ice. Our observations contrast with the conclusion of Timco and Frederking (1993), where data suggested a decrease in peak force with time to peak force. In that study, different impactor shapes resulted in different times to peak force and the conclusions relate more to a comparison of effects of different-shaped impactors rather than a trend for data from any one impactor. The fact that the impact tests of Timco and Frederking (1993) were conducted on floating ice sheets may also have contributed to differences in observed behaviour, particularly for the thinner ice sheets where vertical shear punching of the columnar-grained ice sheet was observed.

Table 5 also lists center pressure, nominal pressure and specific energy, all evaluated at time of peak force. Nominal pressure is defined as the load on the ice divided by the projected area of contact. Center pressure and nominal pressure, like the depths, areas and volumes mentioned above, did not correlate well with the initial test parameters. Center pressure at time of peak force often exceeded corresponding nominal pressure by a large margin, indicating substantial concentration of stress in the ice confined under the center of the projectile tip. This has been observed by others (e.g. Timco and Frederking, 1993). The values of center pressure showed high scatter. This was attributable 

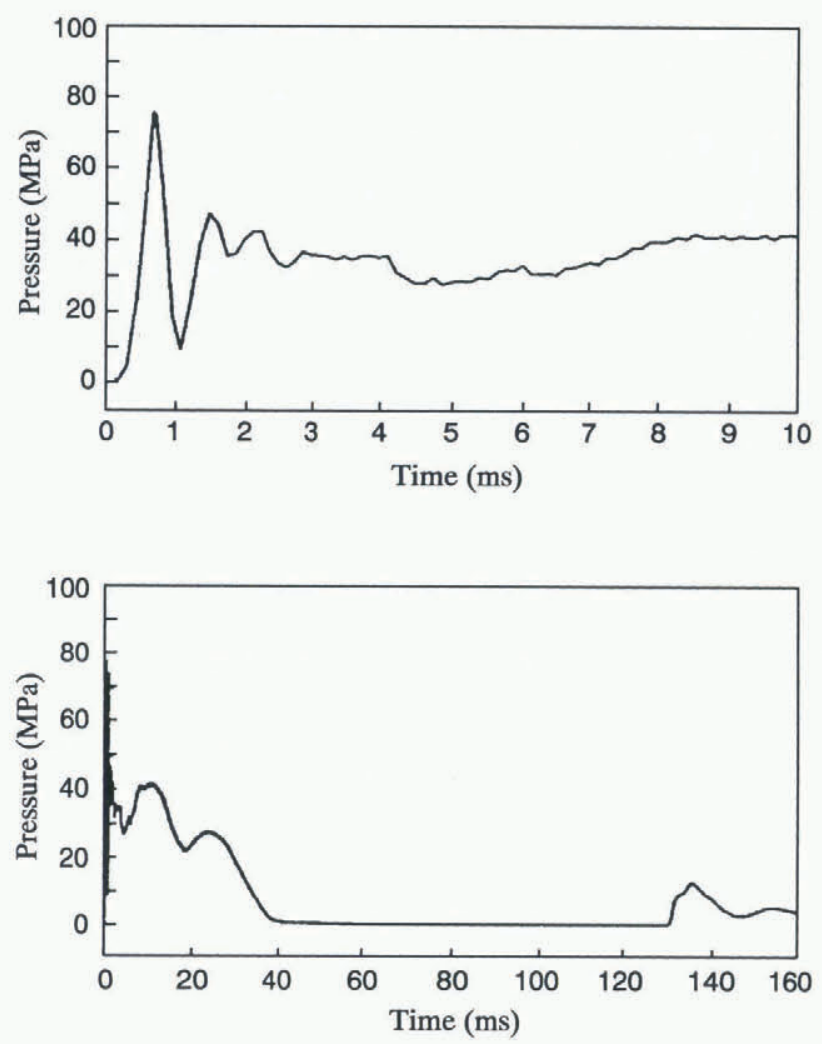

Fig. 7. Plot of projectile center pressure vs time for the first $10 \mathrm{~ms}$ (upper charl) and the first $160 \mathrm{~ms}$ (lower chart) of impact test . No. 10 (ID No. I27X03). A projectile of mass $50.9 .8 \mathrm{~kg}$ was dropped from a height of $0.357 \mathrm{~m}$ on to ice at a temperature of $-8.5^{\circ} \mathrm{C}$.

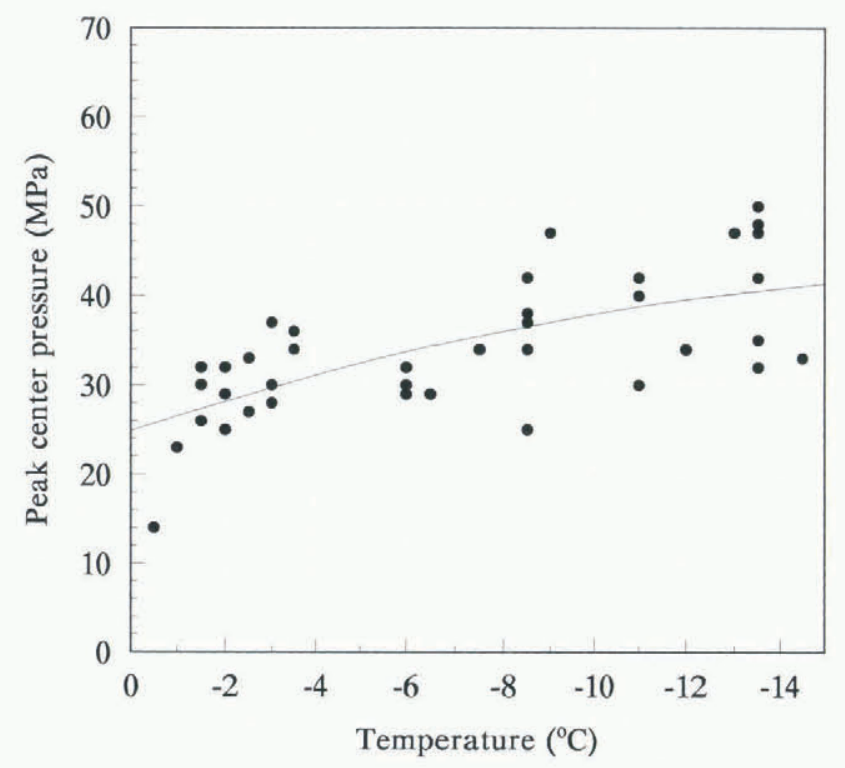

Fig. 8. Plot of peak center pressure vs temperature. The data have been fitted with a least-squares second-order polynomial of the form $y=a+b x+c x^{2}$ where $a=24.85, b=$ -1.734 and $c=-0.04245$.

to uneven breaking of ice underlying the pressure transducer. In some instances, cavities appeared to form temporarily beneath the transducer, leading to a near-zero reading of center pressure. It is noteworthy that for medium-scale indentation experiments, conducted within a grounded iceberg at Pond Inlet (Masterson and others, 1992), average pressures calculated from load and nominal contact area in the early stages of indentation were in the range of the peak pressures reported here. The present

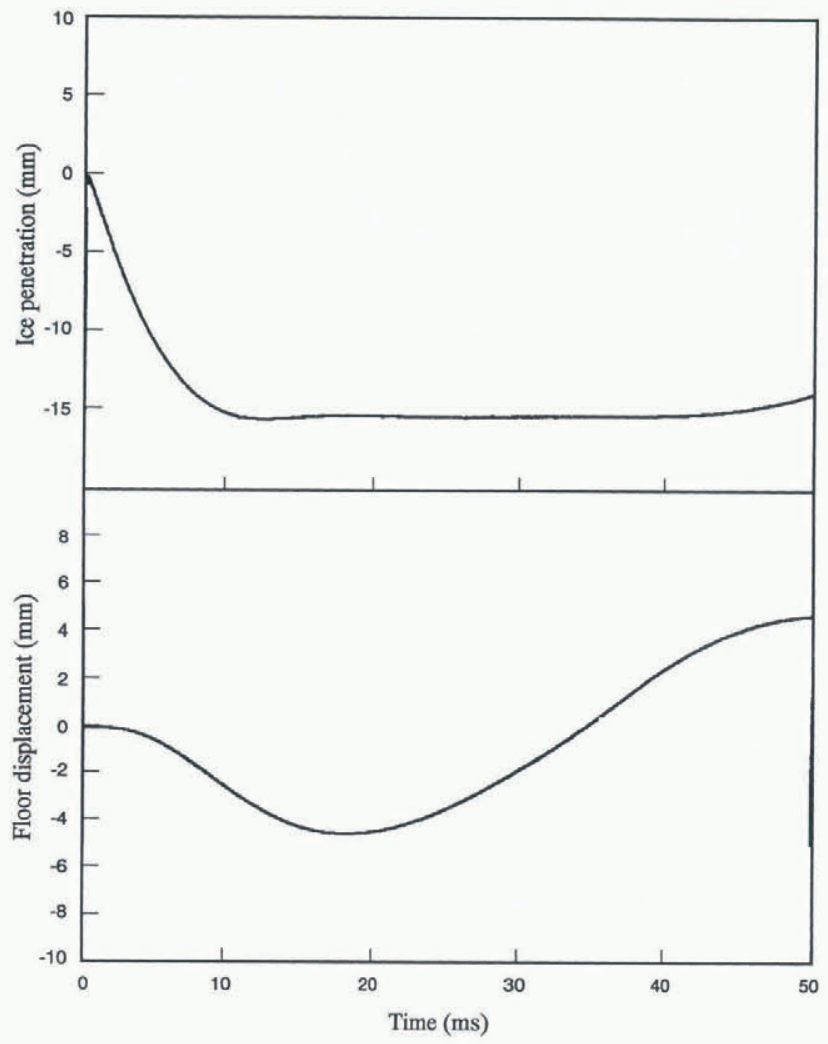

Fig. 9. Plots of ice penetration and floor displacement os time for impact test No. 10 (ID No. I27X03). A projectile of mass $509.8 \mathrm{~kg}$ was dropped from a height of $0.357 \mathrm{~m}$ on to ice at a temperature of $-8.5^{\circ} \mathrm{C}$.

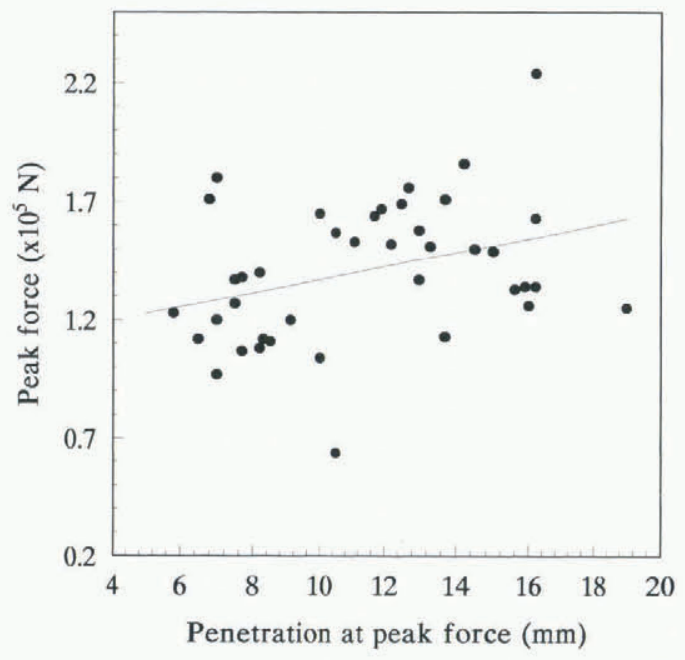

Fig. 10. Plot of peak force is penetration at the time of peak force for all of the impact lests. The dala have been fitted with a least-squares straight line of the form $y=a+b x$, where $a=1.084$ and $b=0.029$.

impact-test program was conducted as a precursor to the Pond Inlet experiments. The magnitudes of the peak pressures reported here are similar to those observed by Timco and Frederking (1993). The pressures recorded by El-Tahan and others (1984) for small-scale impact tests on iceberg ice were lower than those here. The size of the component of their impact apparatus that actually contacted the ice was much smaller than ours or Timco and Frederking's and that may have resulted in their pressure transducer not experiencing full contact during tests, due to uneven breakage of ice beneath the transducer, consequently leading to lower indicated pressures. 


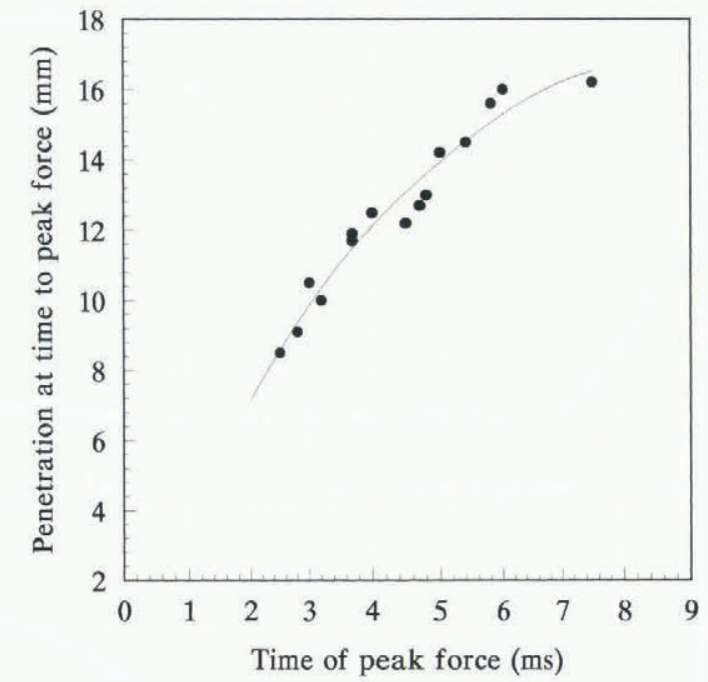

Fig. 11. Plot of penetration us time at time of peak force for the tests where all conditions, except temperature, were the same. The data have been fitted with a least-squares second-order polynomial of the form $y=a+b x+c x^{2}$ where $a=0.46$, $b=3.80$ and $c=-0.22$.

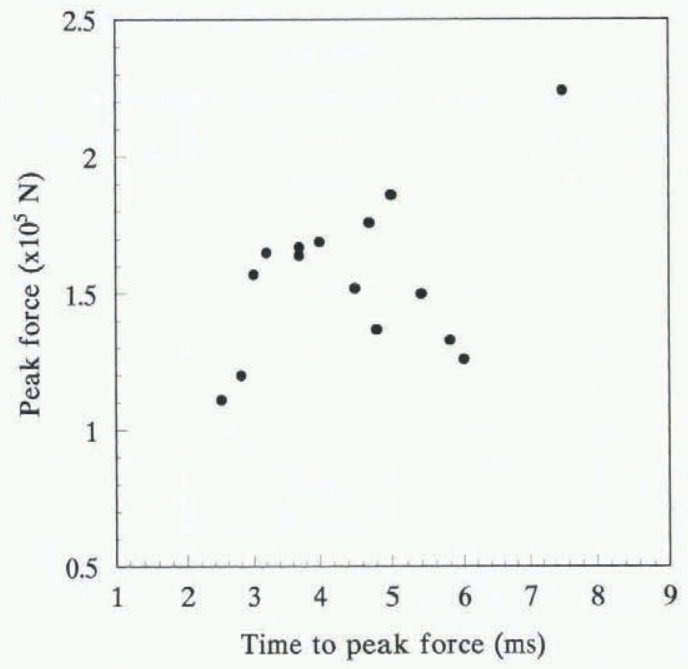

Fig. 12. Plot of peak force vs time of peak force for the tests where all conditions, except temperature, were the same.

Figure 13 shows center pressure vs penetration at time of peak force. The data indicate no correlation between the penetration and the pressure. This suggests that the pressure on the intact ice, where the load force is concentrated, is independent of penetration. Data of Gagnon (1994) have indicated this type of behaviour for crushing experiments on fresh-water ice. The scatter in measured center pressure can be attributed to the random aspect of uneven breaking of ice beneath the projectile tip mentioned previously.

Although considerable scatter is present a dependence of loading rate and peak force (correlation coefficient of 0.35 ) is discernible when data from all tests are plotted (Fig. 14). Loading rate is defined as peak force divided by the time to peak force. Data from Timco and Frederking (1993), for any particular impactor shape they used, also showed a positive dependence of loading rate on peak force and significant scatter.

The measured specific energy was calculated by determining the energy imparted to the ice and then dividing by the crater volume determined from the direct measurement of crater depth at the end of the test. The computed

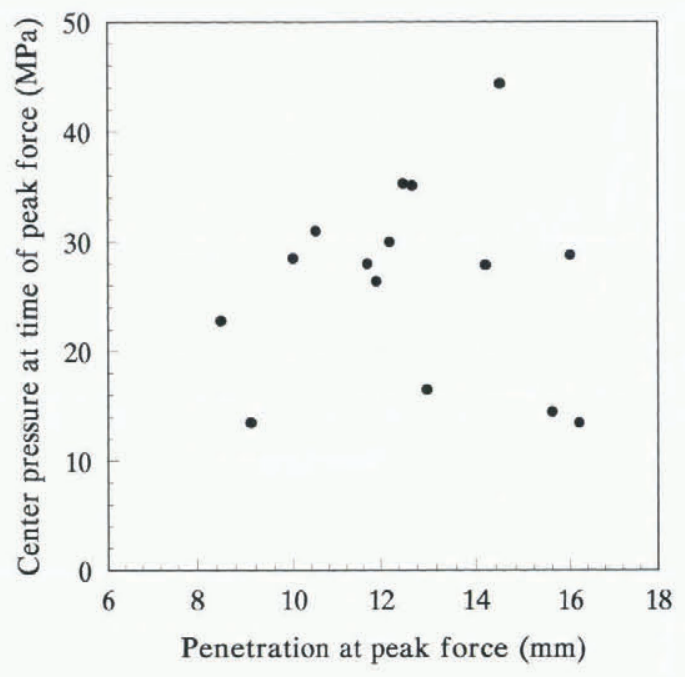

Fig. 13. Plot of center pressure us penetration at time of peak force for the tests where all conditions, except temperature, were the same.

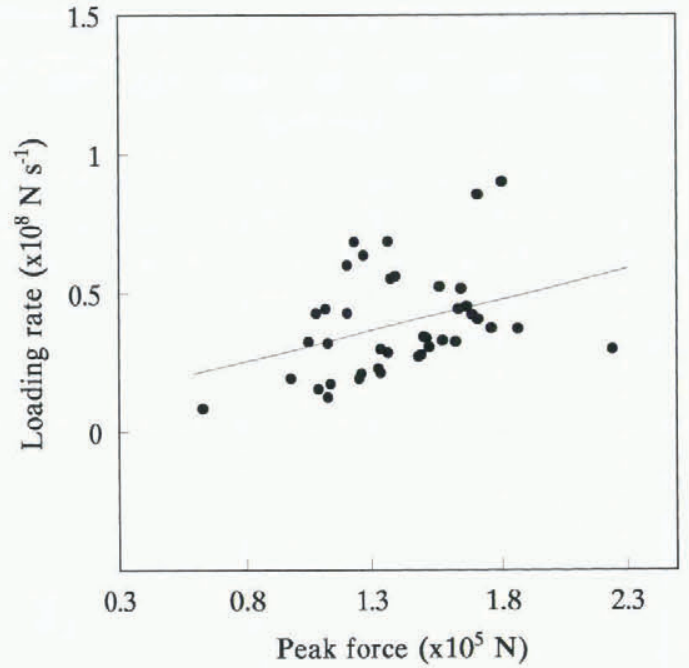

Fig. 14. Plot of loading rate us peak force at time of peak force for all of the impact tests. The data have been fitted with a least-squares straight line of the form $y=a+b x$, where $a=0.077$ and $b=0.222$.

specific energies at the time of peak force and at test conclusion were determined by dividing the computed energy imparted to the ice by the computed crater volume as determined from analysis of the acceleration data. The computed energy imparted to the ice was calculated by integrating the force applied by the projectile over the penetration distance specified by the penetration curve (Fig. 9). For tests performed with the same parameters, except temperature, (i.e. 12-26 in Tables 3-5) specific energies at the time of peak force and at the conclusion of tests were found to decrease with increasing temperature, though considerable scatter is evident (Fig. 15). This trend is perhaps not surprising, given the trend of decreasing peak center pressure with increasing temperature indicated in Figure 8 and is in agreement with other observations (Glen and Comfort, 1983) for the same temperature range.

Table 3 shows measured and computed ice penetrations along with the associated values of projectile-contact area at the conclusion of each of the 40 impact tests. The penetrations, on average, agreed within $8 \%$, while the greatest discrepancy was $23 \%$. Table 3 also lists measured and 


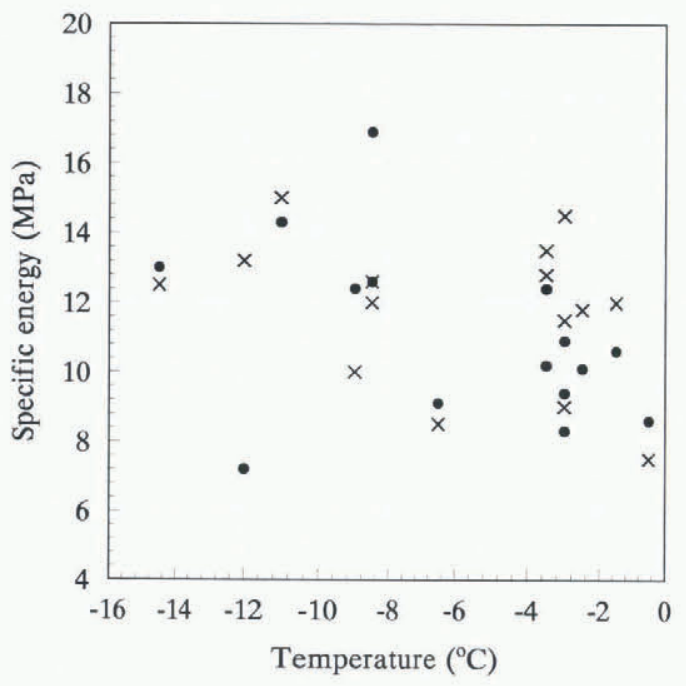

Fig. 15. Specific energy at the time of peak force ( $x$ 's) and measured specific energy at the test conclusion (solid circles) vs temperature. All conditions, other than temperature, were the same for each test.

computed values of displaced ice along with measured and computed specific energies determined as described above. The specific energies correlate reasonably well in view of the compounding of accelerometer error implicit in the procedure used to determine computed specific energy.

Figure 16 shows measured specific energy at test conclusion plotted against measured crater volume. The data for the 40 impact tests have been plotted on one graph, since only a weak and scattered dependence of specific energy on temperature was discernible (Fig. 15). The specific energy is clearly a decreasing function of the crater volume and implied ice penetration. Similar observations have been made by others (e.g. Garcia and others, 1985).

The following explanation appears plausible in describing the dependence of specific energy on crater volume. Several studies have shown that for indentation and impact on ice, the majority of load is borne on areas of relatively

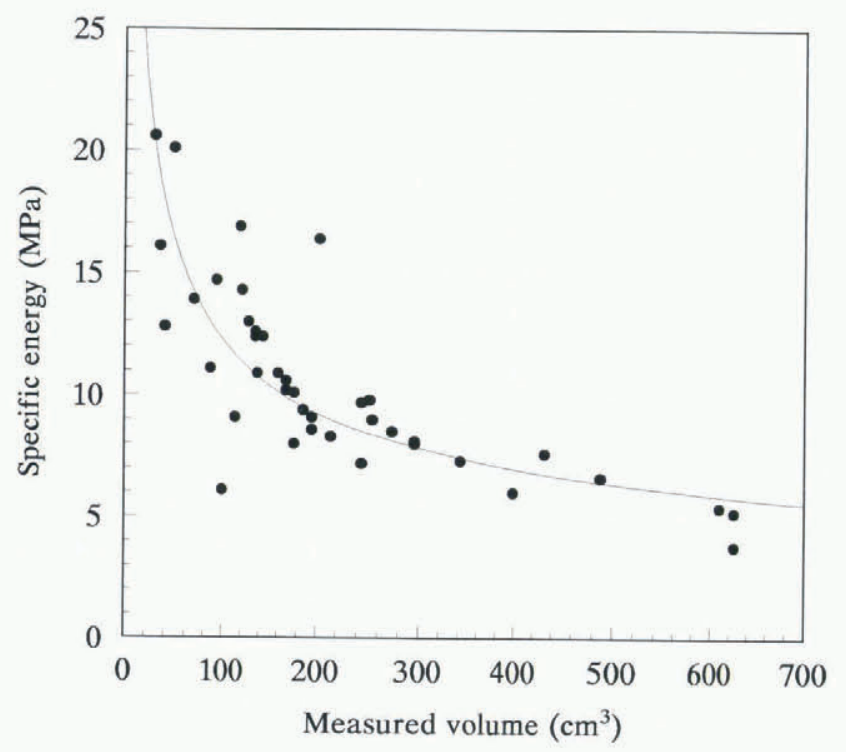

Fig. 16. Plot of specific energy vs measured crater volume at the conclusion of tests for the full range of temperatures $0^{\circ}$ to $-14.5^{\circ} \mathrm{C}$. The data have been fitted with a least-squares power curve of the form $y=a x^{\mathrm{b}}$ where $a=80.653$ and $b=$ 0.409 . intact ice considerably smaller than the nominal contact area, where pressures are in the range of, and often higher than, the highest measured here (e.g. Gagnon, 1994). The size of the zones is roughly in linear proportion to the load supported. A succession of spalling events shapes the hard zones during indentation and it is apparently this mechanism that is behind the observation in numerous studies that load increases roughly linearly with penetration (Fransson and Sandkvist, 1988; Daley, 1990; Gagnon and Sinha, 1991; Gagnon, 1994), even at markedly different scales. The data in Figure 10 are consistent with such a linear dependence within experimental error. Consequently, the energy imparted to the ice varies as the square of the penetration, whereas the nominal volume of ice removed varies as the cube of penetration and hence the specific energy decreases with penetration.

\section{SUMMARY AND CONCLUSIONS}

Thermal profiles were obtained for an iceberg located in Okak Bay, Labrador, Canada. These indicated an internal core temperature at least as low as $-15^{\circ} \mathrm{C}$ and varying temperature gradient, depending on where the temperature probe was inserted on the iceberg surface. The highest temperature gradients in the first few meters of penetration below the ice surface were for the probes inserted above the water line. Surface temperatures for all profiles, above and below the water line, were near $0^{\circ} \mathrm{C}$.

Large specimens of ice were quarried from the iceberg and drop-ball-type impact tests were subsequently performed in the laboratory. Peak pressures at the center of the projectile head during impacts were very high. Peak center pressure increased as temperature decreased and this is thought to be associated with melt-point depression. Specific energy of the crater ice ejected during impacts also increased as temperature decreased. The specific energy was found to be a strongly decreasing function of impact penetration and this is thought to be associated with spalling of ice around the contact zone that leads to a roughly linear increase in load with penetration.

Penetration at time of peak force, loading rate and the time of peak force all correlated positively with peak force.

\section{ACKNOWLEDGEMENTS}

The authors are grateful to many individuals who worked on the field and laboratory aspects of this research. In particular, we thank G. Dinn, presently at Consolidated Technologies Ltd, who served as technical manager of the Labrador ice-collection program, and D. Nevel and J. Benoit, who co-ordinated the work for Mobil Oil Canada Ltd and assisted in the fieldwork. Finally, we should like to thank Mobil Oil Canada Ltd for the use of the data and Hibernia Management and Development Company Ltd for assistance in providing the data.

\section{REFERENCES}

Chin, S. N. and F. M. Williams. 1989. Measurement of impact forces on sea ice. In Axelsson, K.B.E. and L. A. Fransson, eds. POAC 89. The 10th International Conference on Port and Ocean Engineering under Arctic Conditions, June 12-16 1989, Luleă, Sweden. Proceedings. Vol. 2. Luleã, Tekniska Högskolan i Luleă, 638647.

Daley, C. 1990. Ice edge contact: an iterative failure process model. Espoo, Finland, 
Helsinki University of Technology. Faculty of Mechanical Engineering. Laboratory of Naval Architecture and Marine Engineering. (Report from Finnish-CanadianJoint Research Project No. 5 "Ship Interactions with Actual Ice Conditions" Otaniemi 1990/M-103.)

Diemand, D. 1984. Iceberg temperatures in the North Atlantic - theoretical and measured. Cold Reg. Sci. Technol., 9 2), 171-178.

El-Tahan, H., A. S. J. Swamidas, M. Arockiasamy and D.V. Reddy. 1984 Strength of iceberg and artificial snow ice under high strain rates and impact loads. In Lunardini, V.J., ed. Third International Offshore Mechanics and Arctic Engineering Symposium (OMAE), 1216 February 1984, New Orleans, Louisiana. Proceedings. Vol. 3. New York, American Society of Mechanical Engineers, 158 - 165

Fransson, L. and J. Sandkvist. 1988. Pendulum indentation tests on manufactured ice. In Hansen, A. and J. F. Storm, ed. Polartech '88, International Conference on Technology for Polar Areas, June 15-17, 1988, Trondheim, Norwegian Institute of Technology. Proceedings. Vol. 2. Trondheim, Norway, Tapir Publishers, $669-678$.

Gagnon. R. E. 1994. Generation of melt during crushing experiments on freshwater ice. Cold Reg. Sci. Technol., 22 (4), 385-398.

Gagnon, R. E. and P.H. Gammon. 1995a. Characterization and flexural strength of iceberg and glacier ice. . F. Glaciol., 41 (137), 103-111.

Gagnon, R. E. and P. H. Gammon. 1995b. Triaxial experiments on iceberg and glacier ice. f. Glaciol., $41(139), 528-540$.

Gagnon, R. E. and N. K. Sinha. 1991. Energy dissipation through melting in large-scale indentation experiments on multi-year sea ice. In Ayorinde, O. A., N. K. Sinha, W. A. Nixon and D. S. Sodhi, eds. Proceedings, OMAE '91, 10th International Conference on Offshore Mechanics and Arctic Engineering, 2328 June 1991, Stavanger, Norway. Vol. 4. Arctic/Polar Technology: New York, American Society of Mechanical Engineers, 157-161.

Gammon, P. H. and R. E. Gagnon. 1996. Impact experiments on iceberg ice. In IAHR 96, 13th International Symposium on Ice, Beijing, China. Proceedings. Vol. 1, 62-71.

Garcia, N. B., D. Farrell and M. Mellor. 1985. Ice penetration tests. Cold Reg. Sci. Technol., 11 (3), 223236.

Glen, I. F. and G. Comfort. 1983. Ice impact pressure and load: investigation by laboratory experiments and ship trials. In Seventh International Conference on Port and Ocean Engineering under Arctic Conditions (POAC' '83), 59 April 1983, Espoo, Finland. Proceedings. Vol. 1. Espoo, Finland, Valtion Teknillinen Tutkimuskeskus, 516-533.

Goodrich, L. E. 1987. Core temperature measurements on three Arctic icebergs. In Lunardini, V.J., N. K. Sinha, Y. S. Wang and R. D. Goff, eds. Sixth International Symposium and Exhibit on Offshore Mechanics and Arctic Engineering (OMAE'87), March 1-6, 1987, Houston, Texas, Proceedings. Vol. 4. New York, American Society of Mechanical Engineers, 103-107.

Kheisin, D. E. and N.V. Cherepanov: 1970. [Change of ice structure in the zone of impact of a solid body against the ice cover surface.] Probl. Ark. Antark. 34, 79-84. [In Russian.]

Kheisin, D. E. and V. A. Likhomanov. 1973. [Experimental determination of specific energy of mechanical crushing of ice due to impact.] Probl. Ark. Antark. 41, 56-61. [In Russian.]

Likhomanov, V.A. and D. E. Kheisin. 1971. [Experimental study of rigid body/ice impact.] Probl. Ark. Antark. 38, 105-111. [In Russian.]

Loset, S. 1993. Thermal energy conservation in icebergs and tracking by temperature. f. Geophys. Res., 98 (C6), 10,001-10,012.

Masterson, D. M., D. E. Nevel, R. C. Johnson, J. J. Kenny and P. A. Spencer. 1992. The medium scale iceberg impact test program. In IAHR 92. IIth International Symposium on Ice, Banff, Alberta, Canada, June 15-19, 1992. Proceedings. Vol. 2. Edmonton, Alta, University of Alberta. Department of Civil Engineering, $930-966$.

Timco, G.W. and R. M.W. Frederking, 1993. Laboratory impact tests on freshwater ice. Cold Reg. Sci. Technol., 22 (1), 77-97.

\section{APPENDIX}

Three boundary conditions were needed to correct for the three major components of systematic error in the acceleration data. The errors, referred to in the "Analysis of data" section, stemmed from the non-infinite time constant of the accelerometer, inexact zeroing of the accelerometer and the inherent uncertainty in its calibration. The boundary conditions were imposed on data recorded during the time when the projectile had bounced clear of the ice following the initial impact. This time period, referred to in the following discussion as the ballistic trajectory, was relatively well defined in the acceleration records of all 40 impact tests. The ballistic trajectory generally began $30-50 \mathrm{~ms}$ after commencement of the impact and lasted for $60-120 \mathrm{~ms}$. The energy for the bounce was provided by the elastic return to equilibrium of the platform supporting the ice specimens and by relaxation of elastic deformation in the specimen itself.

During the ballistic trajectory the vertical acceleration of the projectile was exactly -1 times the acceleration due to gravity. Accordingly, velocity increased linearly from its absolute minimum, passing through zero at the midpoint of the trajectory duration. The ballistic trajectory of the projectile in test No. 10 is clearly illustrated in Figure 6, beginning at time $=36 \mathrm{~ms}$ and ending at time $=128 \mathrm{~ms}$. The break in contact between ice and projectile is also evident in the center-pressure record shown in Figure 7.

The boundary conditions imposed on the acceleration data in the ballistic trajectory were that velocity at the midpoint of the trajectory be zero and that the acceleration averaged over the first third of the trajectory and the last third of the trajectory be $-9.8 \mathrm{~m} \mathrm{~s}^{-2}$. Application of these boundary conditions yielded three equations in the three parameters used to compensate the previously described systematic error in acceleration output. Accordingly, the parameters were evaluated and the acceleration readings were adjusted to satisfy the boundary conditions exactly. The necessary adjustments were generally so small that they did not visibly change the acceleration vs time curves, although they very significantly modified the velocity and displacement curves computed from the acceleration data. Two additional boundary conditions, namely that the final projectile velocity equals zero and that the final projectile penetration approximates the measured value, were incidentally satisfied in almost all of the test records. This further supported the necessity and validity of adjusting acceleration values to give physical representations of the integrated quantities, velocity and displacement.

Inspection of the projectile displacement curve shown in Figure 6 indicates that the projectile reached a peak negative displacement significantly exceeding the $14 \mathrm{~mm}$ impact-crater depth measured for test No. 10. This overshoot in projectile displacement was the result of recoverable translation of the surface of the ice specimen in the region of the impact crater. The surface displacement reflected a combination of two components. First, the entire ice specimen was translated as the platform and floor supporting the specimen was elastically compressed. Secondly, the ice specimen itself underwent clastic compression resulting in a recoverable displacement of the surface of the specimen relative to the bottom of the specimen.

Because of the spherical shape of the tip of the impact projectile, the area of ice contact and volume of displaced ice were both strong functions of the displacement of the tip of the projectile relative to the ice surface. This relative displacement is subsequently referred to as ice penetration. In order to resolve the ice penetration, recoverable motion of the surface of the ice specimen was modelled as a one-dimensional linear elastic system. This recoverable motion is subsequently referred to as floor displacement, although the displacement was actually distributed throughout the various elastic media underlying the specimen surface.

Within the context of the model described above, the floor displacement in the absence of fluctuations in the load applied to the ice was simple harmonic in form. During those time intervals when there was no relative motion between the projectile tip and the ice surface, the floor-dis- 
placement function could be resolved directly from the accelerometer output. The acceleration record for test No. 10 appears sinusoidal in form during the time interval lying between the dashed lines designated "a" and "b" in Figure 6 . Hence, it has been hypothesized that significant ice penetration did not occur following the time at which projectile displacement reached a maximum (denoted "a" in Figure 6). The displacement curve is then sinusoidal until acceleration reaches zero. At this point, the ice ceases to exert force on the projectile, indicating that the restoring force acting on the ice surface has changed sign. This in turn implies that the ice-surface displacement is zero and hence that the projectile displacement is equal to the depth of the impact crater formed in the ice. The ice and projectile separate following the time of absolute minimum velocity (denoted "b" in Figure 6).

The quantitative floor-motion analysis began with the fitting of a least-squares sine function to the displacement data lying between the time of maximum displacement and the time of minimum velocity. The parameters floated in the sine function were the amplitude and the frequency. The phase was established by setting time zero equal to the time of minimum velocity. Because of the complexity of the assembly of elastic media underlying the specimen surface, no single value of either mass, spring constant or oscillation frequency could be assigned to the entire set of impact data. Accordingly, separate values of these parameters were determined for each test.

The values for effective mass and effective spring constant could not be isolated from the sine fit alone since only the ratio appeared as a parameter in the sinusoidal equation of motion. Separate determination of floor mass or spring constant required knowledge of the energy of the floor oscillations. The energy was calculated by integrating the force applied to the ice surface over the distance through which the surface was deflected. The force was determined directly from projectile mass multiplied by projectile acceleration. The floor displacement as a function of time during loading was not directly specified by the measured data and was therefore modelled using a low-order polynomial satisfying a number of boundary conditions.

Prior to commencement of loading, the three boundary conditions applied to the floor-displacement function were that the position, velocity and acceleration of the floor be zero. At the defined conclusion of ice penetration (point marked "a" in Figure 6) the three boundary conditions were that the velocity of floor displacement be zero, and that the amplitude and acceleration of floor motion be those values determined solely from the least-squares sinusoidal fit. The boundary conditions dictated that a polynomial curve of minimum order 5 be used to describe the floor motion during the time of loading. Accordingly, the six boundary conditions were satisfied exactly by selecting the six coefficients in a fifth-order polynomial. The floor-displacement function during the time of ice penetration (time zero to time "a" in Figure 6) was then given by the sum of a fifthorder polynomial and a sine function fitted previously to the data where the floor motion was assumed harmonic.

Figure 9 shows a plot of the floor-displacement function and the resulting calculated ice penetration for impact test No. 10. The effective floor mass in this test was $4100 \mathrm{~kg}$ and the spring constant was $39 \mathrm{MN} \mathrm{m}^{-1}$. The amplitude of floor oscillation was $0.0046 \mathrm{~m}$ and the frequency was $15.5 \mathrm{~Hz}$. About $16 \%$ of the initial impact energy was imparted to the floor. An average of values obtained for all tests showed an effective floor mass of $2700 \mathrm{~kg}$, and effective spring constant of $2400 \mathrm{MN} \mathrm{m}^{-1}$, an oscillation frequency of $14.2 \mathrm{~Hz}$ and a $16 \%$ fraction of total energy being imparted to the floor. The sum of the ice-penetration function and the floor-displacement function, shown in Figure 9, yields the

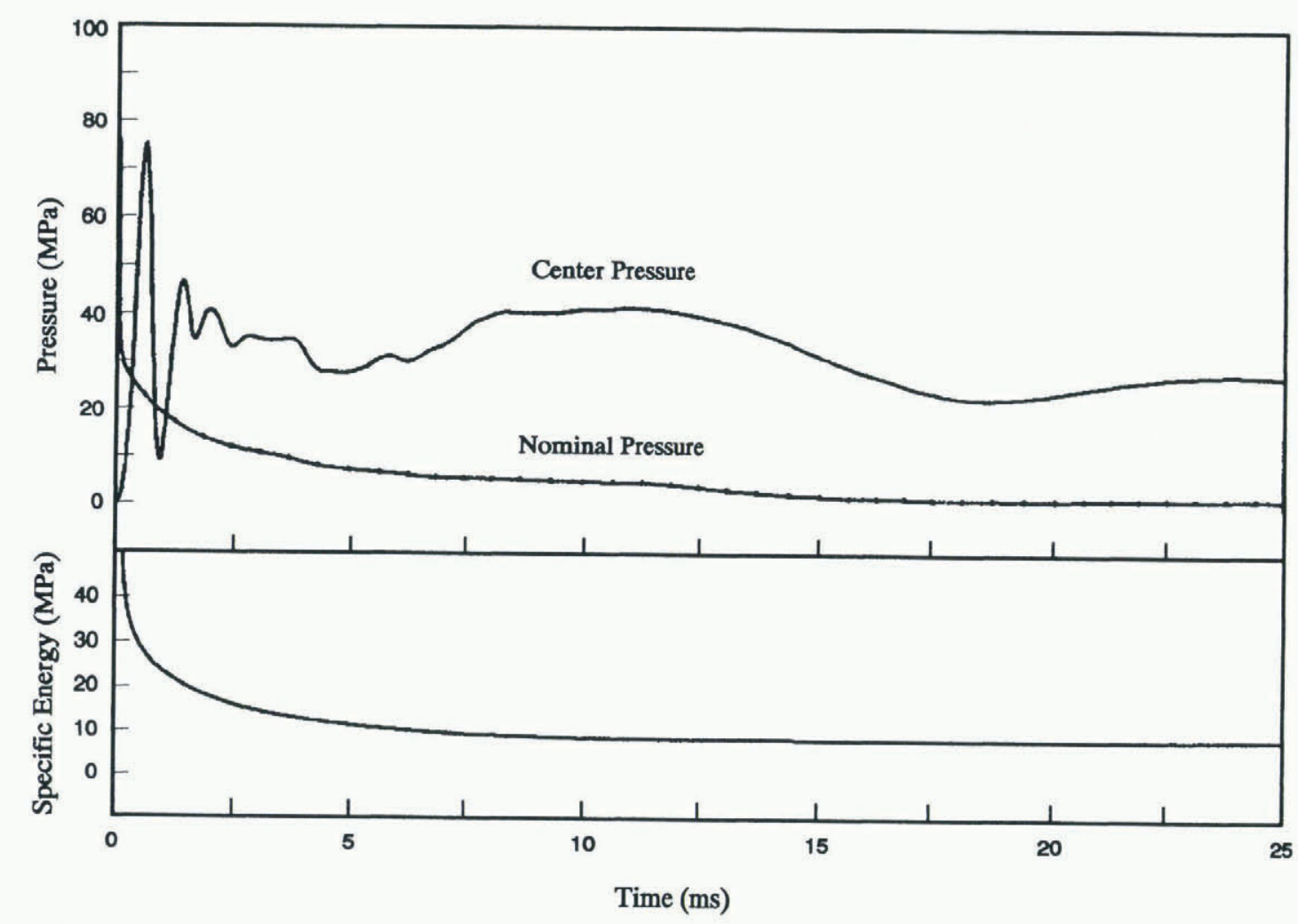

Fig. 17. Plots of nominal pressure, center pressure and specific energy vs time for impact test No. 10 (ID No. I27X03). A projectile of mass $509.8 \mathrm{~kg}$ was dropped from a height of $0.357 \mathrm{~m}$ on to ice at a lemperature of $-8.5 \mathrm{C}$. 
projectile-displacement function shown in Figure 6. The negative slope arising near the end of the ice-penetration curve indicates the separation of ice and projectile which occurs as the downward-directed restoring force acting on the specimen surface becomes significant.

Figure 17 shows the nominal pressure exerted by the projectile in test No. 10 along with the energy per unit volume required to displace ice from the impact crater. The center contact pressure is also included for purposes of comparison. The nominal contact pressure was determined by dividing the force acting on the projectile by the projected area of contact between the projectile tip and the ice specimen. The projected area of contact was the area of the circle formed in the plane of the specimen surface by the perimeter of the impact crater. The contact area was a quadratic function of the ice-penetration distance, that is, the relative distance between the projectile tip and the specimen surface as plotted, for example, in Figure 9.

The specific energy was determined by dividing the energy imparted to the ice by the volume of the resulting crater. The energy imparted to the ice was calculated by integrating the force applied by the projectile over the penetration distance specified by the ice-penetration curve. The volume of displaced ice was taken to be the volume of that part of the projectile tip which lay below the surface of the ice specimen. The volume of displaced ice was a cubic function of the ice-penetration distance. At the commencement of impact, both nominal pressure and specific energy were determined from ratios of quantities, each approaching zero. Since these quantities possessed finite uncertainty, even at time zero, the uncertainty in the ratio near zero tended towards infinity. Accordingly, the charted values of nominal pressure and specific energy for times less than $1 \mathrm{~ms}$ are not reliable and the trend of the data in this region may differ substantially from that illustrated. In particular, the observed tendency of both nominal pressure and specific energy to diverge to infinity at time zero (e.g. Fig. 17) is quite probably not real. The observed monotonic decline in specific energy at times greater than $1 \mathrm{~ms}$ is, however, clearly established by the data.

MS received 10 February 1997 and accepted in revised form 26 June 1997 